\title{
George Sand, Euvres complètes, B. Didier (dir.), 1856. Évenor et Leucippe
}

\section{Lise Sabourin}

\section{OpenEdition}

10 Journals

\section{Édition électronique}

URL : http://journals.openedition.org/studifrancesi/10006

DOI : 10.4000/studifrancesi. 10006

ISSN : 2421-5856

Éditeur

Rosenberg \& Sellier

\section{Édition imprimée}

Date de publication : 1 août 2017

Pagination : 379

ISSN : 0039-2944

\section{Référence électronique}

Lise Sabourin, « George Sand, EFuvres complètes, B. Didier (dir.), 1856. Évenor et Leucippe », Studi Francesi [En ligne], 182 (LXI | II) | 2017, mis en ligne le 01 août 2017, consulté le 09 janvier 2021. URL : http:// journals.openedition.org/studifrancesi/10006; DOI : https://doi.org/10.4000/studifrancesi.10006

Ce document a été généré automatiquement le 9 janvier 2021.

\section{(c) $(1) \&$}

Studi Francesi è distribuita con Licenza Creative Commons Attribuzione - Non commerciale - Non opere derivate 4.0 Internazionale. 


\title{
George Sand, Euvres complètes, B. Didier (dir.), 1856. Évenor et Leucippe
}

\author{
Lise Sabourin
}

\section{RÉFÉRENCE}

GEORGE SAND, CEuvres complètes sous la direction de Béatrice Didier, 1856. Évenor et

Leucippe, édition critique par Claire Le Guillou, Paris, Honoré Champion, 2015, 365 pp.

1 Livre méconnu et marginal, profondément atypique que cet Évenor et Leucippe que Sand s'est sentie obligée de faire précéder d'un avant-propos et d'une longue introduction (en deux temps, «La Création» et «Le Paradis terrestre», sans doute d'ailleurs deux chapitres originels): elle parle de «conte», de «fiction personnelle» pour qualifier cette reconstitution à sa manière des premiers temps de l'humanité.

2 Informée des réflexions scientifiques récentes quoiqu'elle les mentionne peu (la chronologie biblique chère à Cuvier, la filiation générative de l'animalité de Geoffroy Saint-Hilaire, faute de la théorie darwinienne non encore traduite alors en français), mais laissant libre cours à sa fantaisie en marge des dogmes chrétiens comme des affirmations rousseauistes, elle imagine en douze chapitres quasi épiques cette «rêverie» sur l'Éden où s'échappe Évenor, fils hors normes des premières tribus des prairies, et sur le Ténare, où il rencontre la jeune Leucippe, élevée par sa mère adoptive Téléiia, une dive à la race déjà déclinante, mais chargée de transmettre à l'humanité les règles divines de l'amour et du mariage.

3 Ce projet donne lieu à un curieux livre, parfois lassant, mais aussi percutant par quelques phrases de réflexion puissante soudain détachées en plein cœur d'un développement ressenti comme désuet. Tout en déployant son goût personnel des fleurs comme les souvenirs de son voyage en Italie, Sand y fait preuve d'un étonnant syncrétisme: la jeune Leucippe est à la fois une nouvelle Ève née sans Adam et hors de l'Éden, qui n'a donc pas vécu le péché originel, une Vénus sortie enfant innocente et gaie de la mer et un avatar de Moïse porté par les flots jusqu'au creux d'une solfatare 
aride pour être recueillie par une troglodytique survivante de la race des chênes. L'invocation de Téléïa émanée de l'Orphée de Ballanche, les tables de la Loi en dix préceptes hérités des théories du Terre et Ciel de Jean Reynaud, le retour du jeune couple ainsi formé par la quasi-druidesse pour les transmettre à la société humaine, incarnée par Ops, Mos et Sath, aux réactions si divergentes, permettent à Sand désillusionnée après 1848 de croire encore à une régénération associée à un âge d'or revu et corrigé.

4 Claire Le Guillou propose une édition introduite par une présentation descriptive (pp. 7-24), suivie d'une étude de genèse et de réception (pp. 283-355) plus informative sur cette œuvre, née d'une commande pour une série d'Amours illustres à paraître chez l'éditeur Philippe Collier, avec pré-originale pour Mirès dans «Le Constitutionnel». L'incurie du collaborateur Paulin Limayrac, pourtant admirateur fervent de la romancière mais peu pressé d'effectuer les recherches qu'elle lui demandait, la limita à ce seul volume, finalement paru dans «La Presse» du 9 au 31 janvier 1856, puis chez Garnier frères en 1856. Rédigé du 26 juin au 28 août 1855, tandis que triomphait toujours Histoire de ma vie, ce que Sand qualifiait alors d'«ennuyeux roman» quoique son intérêt pour cette «légende» y soit visible reçut un accueil on ne peut plus limité: quelques recensions dans les journaux anglo-saxons, une étude dans la Revue philosophique et religieuse, une réaction d'un rabbin padouan. Malgré des rééditions en 1866,1871 et 1889, le livre resta peu apprécié, sauf de quelques spécialistes en fin de $\mathrm{XX}^{\mathrm{e}}$ siècle. Claire Le Guillou fournit ces articles critiques, en explique l'évolution, explore bien les sources de l'œuvre, finalement facilitées à Sand par les prêts livresques du berrichon Ernest Périgot (outre Reynaud et Leibniz qu'elle connaissait déjà, elle lut ou relut L'Tliade et le mythe de l'Atlantide chez Platon, la gnose de saint Clément d'Alexandrie, Le Paradis perdu traduit par Chateaubriand, la Civilisation primitive de Brotonne et La Chute d'un ange de Lamartine, sans oublier Leroux et Ballanche depuis longtemps appréciés). L'annotation est intéressante, malgré des appels de notes très lourds et une présentation des variantes qui se veut mimétique du manuscrit mais n'est guère lisible. Enfin bibliographie et index de noms et de lieux terminent cette édition critique d'une œuvre qui témoigne de la liberté du «transformisme spiritualiste» propre à Sand. 